
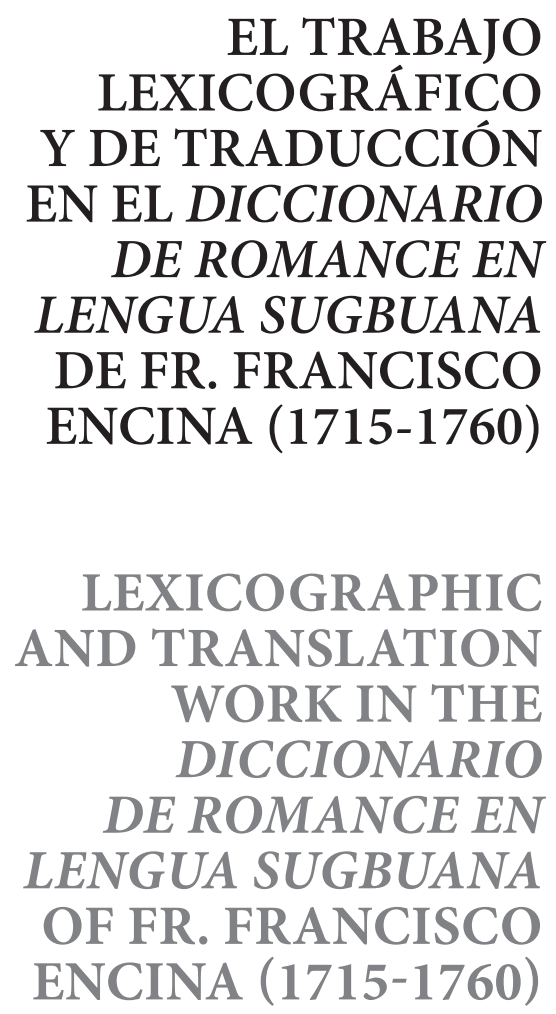
El objetivo principal de este trabajo es presentar la obra del Padre Reverendo Fr. Francisco Encina (O.S.A.) (1715, Ponferrada, León, España - 1760, Cebú, Filipinas), esto es, su Diccionario de romance en lengua sugbuana, de mediados del XVIII, conservado actualmente como Mss/8427 en la Biblioteca Nacional de España. Su análisis permitirá conocer los modelos lexicográficos que el autor sigue para la elaboración de su diccionario. Así como su originalidad como traductor e intérprete legítimo de la fe cristiana en la lengua cebuana, especialmente en tanto a la traducción de los referentes religiosos, y a la denominación de las nuevas realidades indígenas se refiere.

Palabras Clave: historiografía lingüística, lingüística misionera, lexicografía, español-cebuano, Francisco Encina

The main objective of this study is to present the work of the reverend father Fr. Francisco Encina (OSA) (1715, Ponferrada, León. España - 1760, Cebu. Philippines), that is, in his Diccionario de romance en lengua sugbuana, half of the 18th century, now preserved as Mss/8427 in Biblioteca Nacional de España. Their analysis will identify the lexical models that the author continues to prepare its dictionary. And also, his originality as translator and as interpreter legitimate Christian faith in the Cebuano language, especially, in the translation of own religious references and the name of the new indigenous realities.

KEYwORDs: linguistic historiography, missionary linguistics, lexicography, Spanish-Cebuano, Francisco Encina

FeCHA DE RECEPCión: 13/04/2016

FECHA DE ACEPTACIÓN: 18/06/2016 


\section{EL TRABAJO LEXICOGRÁFICO Y DE TRADUCCIÓN EN EL DICCIONARIO DE ROMANCE EN LENGUA SUGBUANA DE FR. FRANCISCO ENCINA (1715-1760)}

\section{LEXICOGRAPHIC AND TRANSLATION WORK IN THE DICCIONARIO DE ROMANCE EN LENGUA SUGBUANA OF FR. FRANCISCO ENCINA (1715-1760)}

María Águeda Moreno Moreno

Universidad de Jaén

1. Intérpretes, traductores, maestros de lenguas

y lexicógrafos

Dentro de la historia general, que caracteriza y singulariza la lingüística misionera, encontramos historias particulares de los que protagonizaron los hechos. El ejercicio de la evangelización en América y Asia generó una actividad ininterrumpida de labor lingüística que vino de la mano de religiosos, vocacionales en su fe e intuitivos gramáticos y lexicógrafos en su hacer, y que además, irremediablemente, se vieron abocados a la práctica de la traducción.

La labor de evangelización y el ejercicio de la traducción pronto se vieron ayudadas por los mediadores en las labores 
de interpretación: bozales, identificados en las propias crónicas de Indias como intérpretes torpes, a diferencia de los ladinos, indios, mestizos o negros, buenos conocedores del idioma castellano. De chasques y faruates, mensajeros indios que servían de correo. Los naguatlatos - naguatato, nahuatato, nahuatlato-, indios o europeos, que comprendían y hablaban la lengua náhuatl y que desde mediados del siglo XVI se ocuparon de la interpretación en las audiencias y asistencia personal de los oidores en sus visitas. La lengua o las lenguas - usado en género femenino- o el lenguaraz, entre otros. O, concretamente en Filipinas "ladinos o naguatatos que conocían suficientemente el castellano" (Borao, 2013: 28), esto es: "personas a caballo entre dos culturas que resuelven el problema de la comunicación” (2013: 29). En definitiva, personajes todos que fueron los intérpretes y mediadores lingüísticos durante la época de la colonización y de quienes bien nos hablan nuestras crónicas y fuentes documentales. Una realidad que por el nuevo escenario conceptualizó nuevos términos, pero que representaba la idea conocida ya en español desde el siglo XIII del trujamán, truchimán o trujimán, del árabe hispánico turğumán, este del árabe clásico turğumān, 'intérprete de lenguas' (Alonso Araguás, 2005).

Por su parte, los religiosos misioneros se entregaron a la tarea de la traducción y la redacción de gramáticas y diccionarios. De modo que el impulso del desarrollo de la actividad lingüística misionera no será otro que la misma evangelización.

Para el caso de Filipinas, escenario y objeto de este trabajo, una muestra de ese esfuerzo misionero lo podemos ver 
de manera explícita en: "la Colección Scheerer de gramáticas y diccionarios de lenguas filipinas existente en la Biblioteca de la Universidad Nacional de Taiwán, que incluye bastantes ejemplares, bien originales o reimpresiones" (Borao, 2013: 24).

La propagación de la fe católica trajo consigo una actividad filológica: el estudio y codificación de los complejos idiomas aborígenes de estas provincias. Esta primera tarea supuso a su vez una importante dificultad. Sin embargo, estos improvisados gramáticos y lexicógrafos demostraron ser pacientes observadores y sufridos estudiosos de una lengua que por primera vez llegaba hasta sus oídos y representaba un mundo desconocido. El diccionario, por su parte, permitió presentar en un orden alfabético la nueva realidad. Se convirtió en un útil y complejo instrumento de trabajo en el que se fusionan distintas realidades y en donde la simbolización de los nuevos sonidos en un código conocido permitió a los ministros destinados a distintos territorios una sólida formación lingüística. Esta labor despertó un gran interés entre los religiosos, tanto es así que en poco tiempo todas las lenguas importantes de las zonas coloniales tenían una gramática o un vocabulario que describía y codificaba estas lenguas.

Pese a todo, si bien el espacio americano está profusamente estudiado, no ocurre lo mismo con el asiático. Sirva de ejemplo, las palabras de García-Medall: "uno de los capítulos más brillantes y olvidados de la historiografía lingüística hispánica es el que se relaciona con la lexicografía bilingüe en tierras asiáticas y, en particular, en las islas Filipinas" (2007: 6). 
Por ello, en este estudio pretendemos acercarnos a la obra de uno de ellos, el Padre Reverendo Fr. Francisco Encina (O.S.A.) (1715, Ponferrada, León, España - 1760, Cebú, Filipinas), lexicógrafo y traductor de la lengua cebuana. Este religioso agustino no publicó ninguna de sus obras, ni las de carácter lingüístico, ni su producción de carácter religioso, de ahí que se hayan mantenido en estado manuscrito, como es el caso de su obra lexicográfica, o que hayan llegado hasta nosotros gracias a publicaciones posteriores a su muerte.

En este trabajo nos vamos a acercar al manuscrito Diccionario de romance en lengua sugbuana (c. mediados del xviII) conservado como Mss/8427 en la Biblioteca Nacional de España. Su estudio pormenorizado nos permitirá conocer de primera mano: 1) datos biográficos y bibliológicos sobre este religioso; 2) su posible filogenia, como la de otros muchos repertorios hispano-filipinos, con el vocabulario bilingüe publicado en América para la lengua náhuatl o mexicana de Fr. Alonso de Molina (1555); así como, 3) determinar su propia originalidad en la codificación de la información léxica, semántica y sintáctica frente a los modelos, motivada, esencialmente, por dos razones, la estructura de la lengua cebuana y la diferencia conceptual entre los dos mundos, el indígena y el europeo.

Todo ello, sin duda, permitirá ver en el diccionario bilingüe el método de dar correspondientes -o equivalentes, glosas y traducciones- de la lengua española en esta otra lengua, la cebuana. Y, como es de esperar, determinará la organización de la microestructura sujeta al tipo de informaciones que se presentan. 


\section{Del autor y su obra}

En el Inventario General de Manuscritos de la Biblioteca Nacional de España, bajo la signatura Mss/8427, manuscrito en papel de $26 \times 20 \mathrm{~cm}$., compuesto por $124 \mathrm{~h}$ y texto escrito en español y cebuano, nos encontramos el Diccionario de romance en lengua sugbuana. Presenta en su portada el título y la declaración de autoría por parte del " $R$ (everendo) P(adre) Pred(icado)r Fr(ay) Fran(cis)co Encina” (fol. 1r) y sin fecha.

Al no estar el manuscrito fechado, los datos con los que contamos en tanto a su edición son los que nos proporciona el registro del Inventario General de Manuscritos de la BNE, en el que se indica que es una edición propia del siglo XIX.

En la Biblioteca Digital Hispánica de la BNE se data entre los años de 1801 y 1900. No obstante, por los datos obtenidos en este estudio sobre el autor y su producción lingüística, el Diccionario más bien parece ser un trabajo de mediados del siglo XviII.

De Francisco Encina son pocas las noticias que tenemos. Por el Inventario General de Manuscritos (1988) de la BNE en la catalogación del Mss/8427, el autor es registrado como "Francisco Encina (O. P.)". Siglas que indican "Orden de Predicadores", la cual es conocida también como orden dominica $y$, a sus miembros, como dominicos. No obstante, a la luz de los datos extraídos en este estudio, entendemos que esto bien puede ser un error en los datos, pues en la nueva catalogación de materiales bibliológicos que se ha hecho en la realización de la Biblioteca Digital Hispánica (BNE), la búsqueda "por autor" en el recurso en línea nos 
proporciona cuatro resultados vinculados a "Francisco Encina", a saber:

1) el manuscrito: Diccionario de romance en lengua sugbuana (c. 1801-1900) de Francisco Encina;

2) el libro editado por Tomás Oliva: Arte de la lengua zebuana sacado del que escribió el R.P.Fr. Francisco Encina (1836, Imp. de Don José María Dayot), del cual se indica que es "Agustino Calzado";

3) el mismo dato hallamos en el libro: Gramática bisaya cebuana del P. Francisco Encina, Agustino calzado, reformada por el M.R.P. Fr. Nicolás González de S. Vicente Ferrer, Agustino Recoleto (1885, Manila: Imp. De "Amigos del País"). Los datos que proporciona Fr. Nicolás González sobre Encina en su obra son muy breves: "P. Francisco Encina, Agustino Calzado, y Cura que fue de Argao" (1885: Amado Lector, 9);

4) Y el mismo dato, de nuevo, en el libro: Arte compendiado de la lengua cebuana por el M.R.P. Ex-Provincial Fr. Julián Bermejo, sacado del que escribió el R.P.Fr. Francisco Encina. Agustinos Calzados (1894, Zambolang, Pequeña tipo-lit. del Asilo de huérfanos, $2^{\mathrm{a}}$ ed.).

Ante esto está clara la existencia de Francisco Encina, agustino calzado, autor de una gramática cebuana. Es difícil creer en la coincidencia de dos religiosos, un dominico y un agustino, con el mismo nombre, ambos interesados por describir la lengua cebuana y compaginando su labor religiosa, con la traductora y la lingüística. Sin embargo, en honor a la verdad, lo cierto es que no existe ningún dato, al menos al que nosotros hayamos podido tener alcance en este estudio, a propósito del diccionario y, por tanto, del autor de este. 
Creemos, por tanto, que se trata del mismo autor, que Fr. Francisco Encina, agustino calzado, en su labor como religioso destinado a la evangelización en las Filipinas llevó a cabo la labor lingüística, como tantos otros religiosos, de elaborar una gramática y un diccionario. El desconocimiento de este último, sin duda, es por su estado manuscrito, lo que ha hecho que, ante la tradición historiográfica, haya pasado desapercibido.

Las pocas noticias y referencias que al respecto hallamos confirman ciertamente la tesis que presentamos. Quien más datos biográficos y bibliológicos nos proporciona sobre este religioso es otro hermano de la Orden de la Provincia del Smo. Nombre de Jesús de Filipinas, Gregorio de Santiago Vela, O.S.A., quien lo incluye como agustino en su Biblioteca Iberoamericana de la Orden de San Agustín (1922: 310-317):

Hijo de Diego de la Encina y Angela Valgoma, vecinos de Ponferrada, provincia de León, nació el año de 1715 y vistió el hábito religioso en el convento de nuestra Señora del Risco. Siendo aún novicio se alistó para las misiones de Filipinas y a su paso por Méjico profesó en el Hospicio de Sto. Tomás de Villanueva el 15 de mayo de 1738, llegando al año siguiente a dichas islas. Fue destinado a Pampanga, donde administró los pueblos de Santor, Gapán, Arayat y Apalit. Padeció graves persecuciones por defender a los indios de las ambiciosas miras del Alcalde mayor D. Baltasar de Cuenca, el cual consiguió que saliese desterrado de aquella provincia. Por este motivo le encontraremos después en Cebú, regentando sucesivamente los pueblos de Argao y Opong. Falleció en este segundo el 14 de julio de 1760 (1922: 310). 
Ante estos datos biográficos una cosa parece clara, el Diccionario no puede ser de principios del siglo XIX, a no ser que se trate de una copia manuscrita del XIX - no obstante, no se señala nada al respecto en el catálogo de la BNE, ni en el mismo documento-, más bien debemos entender que se trata de una obra original de mediados del siglo XVIII, al menos, la que salió de su pluma. Esto, especialmente, por la fecha de defunción del religioso, la cual fue, según los cronistas de la Orden, en el año de 1760. Dato que coincide con los proporcionados directamente en el Arte del agustino predicador, por quien fue discípulo suyo, Fr. Felipe Ruiz, O.S.A., quien señala:

Certifico yo Fr. Phelipe Ruiz, del Orden de N. P. S. Aug." que este Exemplar intitulado Arte de la Lengua Bisaya Zebuana, es el legítimo original, dictado por el M. R. P. Pred. ${ }^{r}$ Fr. Francisco de la Encina, el mismo Sagr. ${ }^{\circ}$ Orf. ${ }^{n}$ Prior, Minro. Doctr. ${ }^{\circ}$ de los Pue. ${ }^{o s}$ de Argao primeramente, y después del de Opong en donde murió en 15 de julio de 1760 , a. ${ }^{\text {s }}$ e cuya voca aprendí la lengua Zebuana, explicándomela arreglado a las reglas de este mismo Arte: Corregido y enmendado por su misma mano: quien en la última vez que tomo la pluma para su corrección, dos días antes de morir, a saber el 12, de Julio de dho Año, por la Noche, en mi presencia, me testifico, que quedaba totalmente satisfecho, y no hallaba, que enmendar otra cosa. Y por su muerte quedo en mi mano junto con el Ministerio; y por verdad, y para que conste lo firmo en este Convento de $S .{ }^{n}$ Pablo de Manila, en 16., del Mes de Septe, de 1792, a. ${ }^{\mathrm{s}}$-Fr. Phelipe Ruiz - (rubricado.) (Cito por Santiago Vela, 1922: 316). 
Todo ello indica que hasta su muerte estuvo trabajando en la redacción y enmienda de su gramática, por lo que suponemos que el Diccionario ya estaba escrito, al menos en 1760. Es así que Fr. Francisco Encina morirá en 1760 dejando su obra lingüística en estado manuscrito, esto es, su Diccionario y su Arte, aunque esta última correría mayor suerte - de ahí que en el ámbito lingüístico por ello sea conocido este autor- pues pronto la gramática se vería en las planchas de imprenta. ${ }^{1}$ En esto también influyó el hecho de que la elaboración del Diccionario de Francisco Encina se desarrolle dentro de lo que se conoce en el ámbito de la historiografía lingüística de Filipinas como "periodo decadente (1770-1840)", esto es:

El comprendido entre 1770 y 1840 , aproximadamente, es una etapa de decaimiento de la lexicografía hispano-filipina. Y ello no solo por el menor número de obras producidas y de lenguas descritas, sino también, y sobre todo, por las dificultades económicas que sufrieron los misioneros lexicógrafos para financiar sus empresas.

\footnotetext{
${ }^{1}$ Sobre el Arte de la lengua cebuana de Fr. F. Encina, Santiago Vela nos dice lo siguiente: " 4 o de 616 págs., más 15 s. n. que ocupa la tabla o índice. Carece de portada y de los preliminares que lleva el original; el título copiado va a la cabeza de la primera página. Se conoce que las pruebas no fueron corregidas con esmero; sin embargo, la impresión es reproducción exacta de la original, y las erratas que puedan notarse en la puntuación y la ortografía del impreso no pueden achacarse al editor que no hizo otra cosa que reproducir el manuscrito. La impresión, por otra parte, es clara y no se hacían mejores en la época en que se supone editado el libro, en las prensas de Filipinas [...]. Los tipos empleados son los mismos de las Pláticas, del P. Tomás de San Lucas, impresas en Sampaloc el 1798; de lo cual puede deducirse que el Arte salió de la imprenta que los PP. Franciscanos tenían en aquel pueblo. [... Se] conjetura que la impresión se hizo por los años de 1804, y así lo repiten otros bibliógrafos, en la imposibilidad de determinar una fecha verdad" (1922: 315).
} 
Todavía hoy, muchos de estos vocabularios manuscritos de fines del siglo xvirI y mitad del xix siguen inéditos, a la espera de los fondos que les permitan salir a la luz. Las causas por las cuales no llegaron a imprimirse muchas de estas obras se suelen desvelar en los muy interesantes prólogos aún inéditos de estas obras, y van desde las guerras contra el holandés y las revueltas de los indígenas a la desastrosa situación de las arcas de las distintas órdenes y gobiernos (García-Medall, 2007: 13).

Es fácil entender que esta realidad hiciera que el religioso misionero no publicara ninguna de sus obras, ni las de carácter lingüístico que hemos señalado, ni su producción religiosa. Así, sus obras se han mantenido en estado manuscrito o han llegado hasta nosotros gracias a publicaciones posteriores a su muerte. ${ }^{2}$

\footnotetext{
${ }^{2}$ Santiago Vela registra su producción religiosa: (1) Cómputo eclesiástico - Ms. en $4^{\circ}$, en idioma pampango, (2) Ceremonias eclesiásticas - Ms. en $4^{\circ}$, en idioma pampango, (3) Provechos de la santa misa - Ms. en 4º, en idioma pampango, (4) Causas de los temblores y truenos - Ms. en $4^{\circ}$, en idioma pampango, (5) $\mathrm{Ca}$ tecismo cebuano - Ms. que se le atribuye, según el P. Castro y (6) Novena del Sto. Niño de Cebú, Manila, 1810. De esta señala: "No sabemos cuándo se editó por primera vez. En los libros de cuentas del convento de Cebú, consta haberse hecho una edición en Manila en 1810. Siempre se ha impreso sin nombre de autor, tanto en la ediciones que se conocen en castellano como en las de la traducción bisaya. Conservamos entre nuestros papeles unas cuantas hojas de una edición antigua de la novena bisaya, con un pedazo de la portada, en la cual, después del título Novena ug pagdayeg sa SSmo. Niño Jesus, se añade al margen lo siguiente manuscrito: «Nga guintucod sa quinatchila ug sinugbuanon sa P. Fr. Fran. ${ }^{\text {co }}=$ Fr. A. Otero.» Que quiere decir, «compuesta en castellano y cebuano por el P. Fr. Francisco de la Encina.» La letra es del Padre Otero y suponemos que estaba bien seguro de lo que afirmaba, cuando a la declaración del nombre del autor del folleto añadió su firma" (1922: 310-311).
} 


\section{Los modelos lexicográficos del Diccionario de romance en lengua sugbuana}

El Diccionario de romance en lengua sugbuana de Francisco Encina carece en su hiperestructura de un prólogo al uso, esto hace que no podamos conocer de mano del autor las características que sobresalen en su obra y los intereses descriptivos particulares del lexicógrafo. Así mismo, el hecho de que la obra se haya mantenido en estado manuscrito hace que tampoco contemos con ningún dato proporcionado al respecto por parte de un posible editor.

Es por ello que solo el estudio directo de la obra y su puesta en relación con obras del momento nos pueden traer los datos suficientes para saber qué modelos lexicográficos pudieron ser útiles en la tarea de confección del diccionario.

\subsection{La ordenación lexicográfica}

Dado que no se mencionan las fuentes utilizadas, bien podría ser que conociera y siguiera muy de cerca la obra de Fr. Diego Bergaño (1690-1747), Vocabulario de la lengua pampanga en romance ([1732] 1860). Esta hipótesis parte de los datos bibliográficos obtenidos sobre el padre Encina, los cuales nos hablan de cómo este se sirvió de la obra gramatical de Diego Bergaño, Arte de la lengua pampanga (Manila, 1729), para realizar su Arte sobre la lengua cebuana. A saber, en la última página del manuscrito de la gramática de Encina aparece un testimonio de autenticidad de autor firmado por su discípulo Fr. Felipe Ruiz, bajo dicho testimonio: "se hace constar que el Arte del P. Encina es reproducción del 
pampango del P. Bergaño" (Vela, 1922: 316). El mismo Santiago Vela da fe de ello:

Y así es la verdad que hemos comprobado nosotros mismos: las advertencias proemiales y varios capítulos están copiados al pie de la letra, sin otro trabajo que traducir al cebuano los ejemplos pampangos. Queda, sin embargo, mucha parte del texto que pudiéramos llamar propia del P. Encina, en la cual discurre como consumado bisayista y experto observador del lenguaje de los indios en cada región, que siendo siempre el bisaya cebuano, existen no obstante diferencias notables en el modo de hablarle y en la significación de muchos términos, anotando el autor hasta con minuciosidad en algunos casos las particularidades que no debe ignorar el que se dedique al estudio del idioma (1922: 316-317).

No obstante, en cuanto a los diccionarios se refiere, nuestra comprobación de las dos obras no muestra que sean obras gemelas, ni siquiera medianamente similares: ni en el tratamiento lexicográfico ni en el corpus léxico son dependientes una de otra, mostrando la obra de Bergaño una mayor complejidad, tanto en el tratamiento descriptivo lexicográfico como en el número de voces que lista en su corpus.

Es más, la misma disposición unidireccional de lenguas en la ordenación lexicográfica es distinta: pampango(lengua filipina)-castellano en la obra de Bergaño y castellanocebuano(lengua filipina) en la de Encina, esto, tal y como señalan claramente los títulos de las obras: Vocabulario de la lengua pampanga en romance y Diccionario de romance en lengua sugbuana, respectivamente. 
La ordenación español-lengua filipina se justificaba como una cuestión pedagógica fundamental que partía del mismo modelo del Vocabulario nebrisense y que en América reprodujo prontamente el Vocabulario en lengua castellana y mexicana (1555) de Alonso de Molina. No obstante, también encontramos de manera exclusiva el orden inverso, ${ }^{3}$ como en el Vocabulario de Bergaño, que se explica con el fin de: "dar luz á las obscuridades de las voces pampangas" (1860: Aprobación del R. P. Predicador Fr. Casimiro Díaz. 1732). Sin duda justificada la organización macroestructural por razones evangélicas, como propósito global, y por la enseñanza de lenguas, como propósito derivado (Zimmermann, 2004: 12-13), a saber: "declarar la genuina significación, y acentos de los vocablos de este idioma (medio tan inevitable, cuanto preciso para alimentar á tantas almas, cuantas ansiosas, piden el pan de la Doctrina Evangélica)" (1860: Á los RR.PP. y celosos Ministros de la Provincia de la Pampanga. Mis PP. $y$ hermanos, Diego Bergaño, 1732). Sirva de ejemplo:

\footnotetext{
3 "Los franciscanos y otras órdenes en la isla partían de la ordenación fundamental español-lengua filipina, a la manera de Pedro de San Buena Ventura para el tagalo (1613) y tal como había hecho Alonso de Molina en 1555 para el náhuatl en Nueva España, los agustinos y miembros de otras órdenes hacían lo inverso, esto es, daban más importancia a la parte lengua filipina-español. Tal vez la razón sea de índole pedagógica o, tal vez, haya de buscarse en una influencia exógena importante: hacia 1630 se traduce al español, en Manila, una obra elaborada por los jesuitas portugueses que habían sido residentes en Japón. Tal obra, impresa en Nagasaki en 1603 y 1604, el anónimo Vocabvlario da Lingua de Iapam com a declaração em Portugues, feito por algvns Padres e Irmãos da Companhia de Iesv, fue traducida al español, posiblemente por el $\mathrm{P}$. Ezquivel, entre otros religiosos, y publicada anónimamente en Manila en 1630. Dicho vocabulario "solo" contenía la parte japonés-portugués, con una extensión de más 32000 entradas, esto es, el doble de las que hallamos en la obra de San Buena Ventura (1613) para el español-tagalo, que no pasa de las 16000" (García-Medall, 2007: 11).
} 
aguiap. (pp.) N.S. Ampolla, ó fuego de la boca. V. act. y su prot. Brotar, Aguiapan, el que las tiene, por la partic. an, como gumian (Bergaño [1732] 1860: s.v.).

Por su parte, la ordenación castellano-cebuano del Diccionario bilingüe unidireccional de Francisco Encina no muestra un esquema de significación tan sencillo. La parte castellana no aparece lematizada siguiendo los modelos al uso, es más, es la parte castellana la que ofrece el contenido semántico de la lengua filipina. Podríamos decir que lo que funciona como lema, sometido al orden alfabético, bien se ofrece como correspondiente o correspondientes léxicos del cebuano, esto es, equivalentes, glosas y/o traducciones en castellano. De ahí que la organización de la microestructura esté regida a partir de otro tipo de informaciones.

\subsection{Aspectos microestructurales}

No cabe duda de que Francisco Encina, como tantos otros religiosos que se emplearon en la labor lexicográfica en las Provincias, no ofrece un método original, es así que en estas obras podemos advertir claramente los modelos lexicográficos que facilitaron la tarea de hacer diccionarios. En este sentido, de sobra es conocida la influencia que la obra lexicográfica de Nebrija tuvo en América, sin embargo, en tanto al caso de la lexicografía hispano-filipina se refiere, el modelo directo es otro, a saber: el primer vocabulario bilingüe publicado en América para la lengua náhuatl o mexicana de Alonso de Molina (1555) (Sueiro, 1999; Ridruejo, 2001, 
2003 y García-Medall, 2004 y 2007, entre otros). En palabras de García-Medall:

$\mathrm{Al}$ enfrentarnos a la labor lexicográfica misionera en Filipinas [...] se nos plantea la posibilidad de que el modelo nebrisense ya no se aplique de modo tan directo (2004: 206) [...]. La elaboración de vocabularios de lenguas filipinas en el siglo XVII se anclaba en la elección léxica impulsada por Nebrija a fines del s. Xv, pero a través de sus seguidores renacentistas y barrocos mesoamericanos, especialmente de Alonso de Molina (1555 y 1571) (2004: 228).

Y todo esto, sin duda, justificado por el hecho de que para hacer la Carrera de Filipinas era obligado viajar hasta Nueva España. Su paso por México para subir al Galeón de Manila desde el puerto de Acapulco obligó a muchos frailes a atravesar las tierras mexicanas e, incluso, a residir en ellas - tal es el caso, como hemos visto en los datos biográficos aportados de Fr. Francisco Encina, quien al menos pasó parte de los años de 1738 y 1739 en América- (Vela, 1922: 310).

Es fácil pensar que estos religiosos conocieran la obra de Alonso de Molina (1555 y 1571) durante esta primera etapa americana de su viaje. Y no es extraño, por tanto, que encontremos similitud entre el modelo lexicográfico de la obra mesoamericana y el Diccionario hispano-filipino de Encina. Y esto, especialmente, en tanto a la microestructura lexicográfica se refiere. Para entender esto en toda su extensión es necesario saber, como bien señala Romero a propósito de la obra de Molina, que: 
El vocabulario castellano-mexicano y mexicano-castellano manifiesta una organización en la microestructura que resultaría impensable aplicar en lexicografía actual, pero que para en aquel entonces era el único método disponible para crear una obra de esta magnitud con fines de evangelización. Es a partir de este hecho que para la descripción del diccionario de Molina el término lema resulta insuficiente en el conocimiento de la obra del misionero, bien porque lo que se reconocería como lema hoy en día no corresponde al hipotético 'lema' del diccionario bilingüe, bien porque la información de tipo gramatical (morfológica, sintáctica o semántica) que acompaña a la entrada en el vocabulario del franciscano quedan fuera de los límites de lo que es reconocido como lema (2013: 52).

Dicha organización microestructural tiene la misma disposición en la obra de Encina. La entrada o palabra(s)cabecera que se corresponden con la parte castellana no están sometidas a un proceso de lematización representado por una unidad autónoma, tal y como hoy lo entendemos. El esquema microestructural en este caso ofrece lo que se conoce en lexicografía como lema complejo, desde el punto de vista formal, estos lemas son sintagmas cuya estructura misma los presenta como partes de un todo y aparecen dotados de un sentido de particularidad por aparecer uncidos por el proceso de traducción a la lengua cebuana. De modo que el lema es, en realidad, simples partes de un sintagma oracional del tipo $\mathrm{A}=\mathrm{B}$. Los lemas a los que nos referimos presentan la siguiente forma. Véase los ejemplos en (1).

(1) Lemas complejos en español con equivalente léxico en lengua cebuana: 


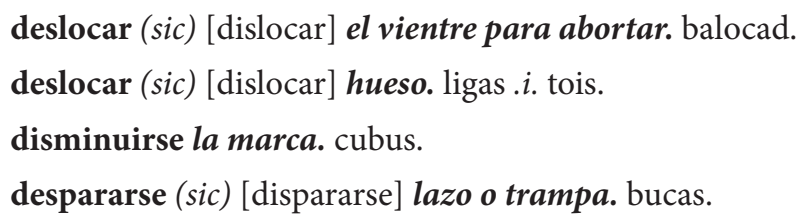

(Encina, m. s. XviII: s.v.)

Estos lemas no son unidades fraseológicas sometidas a un proceso de lematización, al contrario, son estructuras con función sintáctica, en los casos señalados, la propia de $\mathrm{V}+\mathrm{OD}$. Este modelo lexicográfico microestructural ha sido habitual en la práctica de la lexicografía española desde nuestros primeros diccionarios. Lo encontramos en Nebrija, Autoridades, Terreros, etc., y también lo vemos en la obra americana de Alonso de Molina (1571). Romero (2013: 52) estudia los casos de:

i. Atar plumas ricas, juntandolas para ponerlas en algun plumaje, o en alguna imagen que se haze de pluma. nic, tzinychotia. vel. nitla. tzinichotia.

ii. Reluzir las piedras preciosas o los peces dentro del agua con el mouimiento que hazen, o el ayuntamiento de las hormigas o las lagunas y campos, o las gentes ayuntadas por el movimiento que hazen. cuecueyoca.

iii. Tez de alguna cosa liquida y quajada como la lapa o nata de leche quaxada o de poleadas, quando estan frias o de almidon o de cosa semejante que tiene tez enla sobre haz. yxtzotzoliuhca yn atolli. vel. Ixtetzauaca.

Según la autora y estudiosa del texto mesoamericano, es la lengua indígena la que obliga al lexicógrafo a desarrollar 
este planteamiento lexicográfico de uso de una paráfrasis: "introducir una especie de explicación en la parte castellana, con el propósito de recuperar toda la sustancia del contenido de la palabra indígena" (Romero, 2013: 52).

Y como vemos, el método no solo sirvió para la lengua náhuatl, las lenguas filipinas y su carácter de lenguas aglutinantes hizo que la realidad psicológica de la palabra como unidad lexicográfica no sirviera para la codificación léxica en el diccionario, de ahí que, el lexema simple como equivalente no fuera viable. La práctica obligaba a buscar recursos más rentables para la descripción del léxico de estas lenguas. Es así que el lema pierde su carácter de unidad paradigmática y se convierte en una unidad sintagmática contextualizada en un molde discursivo. Ejemplo de esto en (2).

(2) Lemas complejos con información semántica y sintáctica:

acostarse. higda (esto es) ligad

acostarse con otro. dulug.

acostarse en una manta dos. sun-ot.

acostarse de lado. taquilid.

acostarse boca arriba. hayang.

acostarse en el suelo a la larga. hogud.

acostarse a dormir las aves. hulun .i. hulup.

acostarse atravesado. balabag.

acostarse el niño en su camita. colato.

acostarse animal quadropido. labug.

(Encina, m. s. XVIII: s. v.) 
El lema se carga, de este modo, de contenido semántico, sintáctico y contextual. La selección léxica de los actantes, sirva de ejemplo: acostarse ${ }_{[\mathrm{SN} \text { Suj] }}$ las aves, el niño o el animal quadropido (Encina, m. s. XVIII: s.v.) no son expresiones innecesarias, ya que representan unidades conceptuales diferentes en la lengua indígena, esto es: hulun, colato, labug, $y$, aunque a primera vista parezca que se alarga interminable e innecesariamente el listado macroestructural, verdaderamente los conceptos cebuanos no se repiten.

No cabe duda de que esta codificación combinada de información léxica, semántica y sintáctica está motivada por dos razones principales: la primera, por la propia estructura de la lengua cebuana, estructura propia de las lenguas aglutinantes, lo que lleva consigo la dificultad intrínseca para encontrar un equivalente paradigmático dentro de la lengua castellana; y la segunda, por la diferencia conceptual entre los dos mundos que se presentan, el indígena y el europeo. Sirva de ejemplo las voces que permiten nombrar la serie de sucesiones que inscribe el parentesco familiar o las relaciones sociales, para las cuales Encina usa sistemáticamente el lema complejo, en (3).

(3) Lemas complejos para significar el parentesco familiar y/o las relaciones sociales:

nombre afable con que llaman a los mayores. amba. nombre en que valiente a amigo. bangot.

nombre afable para llamar abuelos y abuelas. baba .i. popo. nombre afable para llamar a las muchachas. yrang .i. yorday. nombre afable para los muchachos. yrong .i. iti ongcoi. nombre que da el indígena de qualquiera. arma. 
nombre con que el sobrino llama a la tia. yaya.

nombre que da al iracundo al esclavo. oliproc .i. olipons.

nombre de los vbes (sic) [bebes] pequeños. puspus .i. palucpuc.

nombre de cariño después chicos. titin.

(Encina, m. s. XVIII: s.v.)

El esquema microestructural complejo del lema se constituye sistemáticamente en el Diccionario hispano-filipino con una palabra-núcleo más un complemento que lo actualiza sintáctica y semánticamente. Y que puede ofrecer diferencias según sea la categoría gramatical del núcleo:

i. Los sustantivos. En el caso de los lemas complejos cuya estructura sintagmática es un sintagma nominal, el sustantivo aparece actualizado semánticamente mediante un adyacente nominal o preposicional. Sirva de ejemplo (4).

(4) Lemas nominales complejos con adyacentes modificadores:

abalorte $_{\text {[núcleo SN] }}$ de color parecido al oro ${ }_{[\text {SPrep] }}$

abalorios $_{[\text {núcleo SN] }}$ blancos $_{[\text {Ady] }}$

(Encina, m. s. XviII: s.v.)

No obstante, es también habitual hallar casos en los que el sustantivo-núcleo del SN solo ofrece una conceptualización general, tan ambigua que solo se contextualiza y toma significado pleno gracias al adyacente que lo identifica semánticamente, en (5) y (6).

(5) Lemas complejos para identificar los distintos conceptos de 'lugar': 
$\operatorname{lugar}_{[\text {núcleo SN] }}$ último o descanso de la escalera $\operatorname{lugar}_{[\text {núcleo SN] }}$ patente $\operatorname{lugar}_{[\text {núcleo SN] }}$ decierto (sic) [desierto] donde enterraban $\operatorname{lugar}_{[\text {núcleo SN] }}$ destinado para poner alguna cosa lugar $_{[\text {núcleo SN] }}$ donde se juzga

(Encina, m. s. XVIII: s.v.)

(6) Lemas complejos para identificar los distintos conceptos de 'medida':

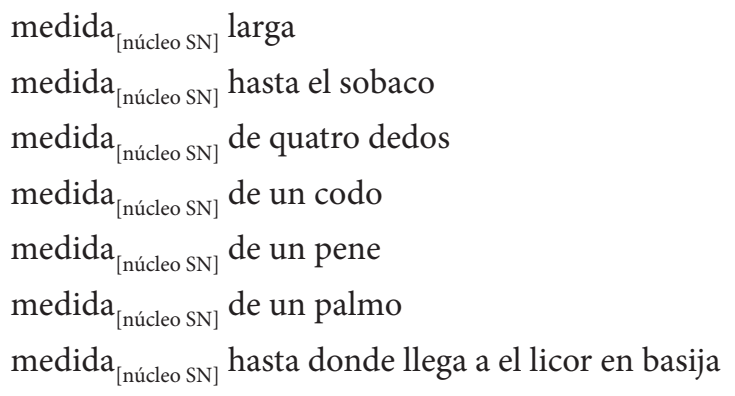

(Encina, m. s. XVIII: s.v.)

ii. Los adjetivos. El lema complejo cuyo núcleo son adjetivos contiene elementos identificadores - 'cosa' / 'persona', entre otros-, que marcan el comportamiento sintáctico del adjetivo como modificador, al tiempo que presentan los rasgos inherentes de selección léxica del adjetivo. La estructura lemática ofrece un esquema sintagmático alterado en español, al poner primero el modificador. Esto es así porque el modificador actúa como palabra-entrada a la que el lexicógrafo da el equivalente en cebuano, en (7).

(7) Lemas complejos con elementos que marcan la selección léxica del adjetivo: 
abarraganada, hombre y mujer. laye .i. hunay.

abarraganada de casado. sapas.

abatida cosa. ubus.

abominable cossa. maluud .i. mangilad.

blanda carne. mahomoc.

blando y modesto en hablar. manayanaya.

divina cosa. lairo.

recio viento. mahoros.

rellena cossa. dasuc.

vil hombre. bañaga.

(Encina, m. s. XviII: s.v.)

iii. El verbo. Los lemas complejos cuya estructura sintagmática es un sintagma verbal, la selección léxica del verbo viene a indicar el régimen y construcción sintáctica de este. Así en la estructura sintagmática se seleccionan actantes como el sujeto, el objeto y complementos circunstanciales, en (8), (9) y (10). Pero además, también se registran estructuras predicativas que se construyen con verbos plenos y añaden a la predicación principal otra secundaria, en (11).

(8) Lemas verbales complejos con selección léxica de objeto:

ablandar lo duro ${ }_{\left[\mathrm{SN} \_ \text {complemento directo] }\right.}$ bunol i. homoc.

ablandar frutas $_{\left[\mathrm{SN} \_ \text {complemento directo] }\right.}$ a golpes. ban og .i. bonol bonolon.

ablandar mugre de olla $\mathbf{a S N}_{\left[\mathrm{C}_{-} \text {complemento directo] }\right.}$ remohandola. hulom .i. lubag.

abrir la boca ${ }_{\left[\mathrm{SN}_{-} \text {complemento directo] }\right.}$ nga nga. 
mover la cabeza ${ }_{\left[\mathrm{SN} \_ \text {complemento directo] }\right.}$ al dormido despertándolo. ligang .i. galo.

ojear aves $_{\left[\mathrm{SN} \_ \text {complemento directo] }\right.}$ con las manos. palid palid.

(Encina, m. s. XVIII: s.v.)

(9) Lemas verbales complejos con selección léxica de sujeto:

moverse alguno ${ }_{\left[\mathrm{SN} \_ \text {Sujeto] }\right.}$. lihoc.

ojear la vestia ${ }_{\left[\mathrm{SN}_{-} \text {Sujeto] }\right.}$. capai capai.

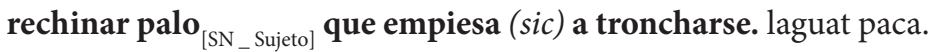
rechinar la cavesa $(s i c)_{\left[\mathrm{SN}_{\text {_ }} \text { Sujeto] }\right.}$ en la almoada. olon .i. uraray.

saltar el agua ${ }_{\left[\mathrm{SN} \_ \text {Sujeto }\right]}$. calbo .i. ticalbong.

saltar peze ${ }_{\left[S N_{-} \text {Sujeto] }\right.}$ huyendo. gusa .i. alac, acal.

(Encina, m. s. XVIII: s.v.)

(10) Lemas verbales complejos con selección léxica de complemento circunstancial:

abrazar con fuego ${ }_{[\text {SPrep] }}$. silab.

maltratar con obra o desprecio ${ }_{[\mathrm{SPrep}]}$. tampalas .i. dagmal.

mostrar con el dedo ${ }_{[S P r e p]}$. todlo.

perseguir por odio $_{[\mathrm{SPrep}]}$. domut.

salir al encuentro ${ }_{[\mathrm{SPrep}]}$, agbat .i. tagbo

(Encina, m. s. xviII: s.v.)

(11) Lemas verbales complejos con selección léxica de complemento predicativo:

ablandar obstinado o penitente [complemento predicativo] alam alamo. 
abrazar luchando
abrir destapandemento predicativo]
mostrar manifistando
[complemento predicativo]
muelat.
[complemento predicativo]

(Encina, m. s. XVIII: s.v.)

iv. Adverbios, interjecciones y partículas. Finalmente, Encina también registra en su Diccionario entradas con lema complejo para dar la equivalencia castellana de adverbios, interjecciones y partículas propias de la lengua cebuana. En estos casos en particular, el lema complejo contiene un indicador gramatical que selecciona la categoría a la que pertenece, con un equivalente léxico y/o una etiqueta semántica. Los listados son extensos, lo que demuestra el conocimiento gramatical que tenía el religioso de la lengua cebuana, es más, solo en estos casos encontramos un esquema léxico múltiple en la (L2), esto es, la lengua cebuana. Seleccionamos algunos casos para su ejemplo, en (12), (13) y (14).

(12) Lemas complejos para adverbios: identificador gramatical, equivalente léxico y/o etiqueta semántica:

adverbio de lugar aquí. ari .i. diri, dinhi, ngari, nganhi.

adverbio de lugar alla. adto .i. ngadto, tua tutat.

adverbio advertiendo o amenazando. baya.

adverbio prometiendo de hacer algo después. ugalingda.

adverbio que significa lo bastante ni mucho ni poco. uya uya $i$. jgo casarangan.

adverbio de tiempos pasados. sanhil .i. casanhi.

(Encina, m. s. XVIII: s.v.) 
(13) Lemas complejos para interjecciones: identificador gramatical, equivalente léxico y/o etiqueta semántica:

interjección del que se admira o se queha (sic) [queja]. aba. interjección alabando. anin .i. anindot. interjección del que se lastima de otro. alaor .i. anogon. interjección del que manda socorrer. ana. interjección ilativa para tanto. yanssi, busa .i. daro. interjección del que tiene orror $\mathrm{o}$ asco. ysi.

(Encina, m. s. XVIII: s.v.)

(14) Lemas complejos para partículas: identificador gramatical, equivalente léxico y/o etiqueta semántica:

partícula que forma el nominativo. ang. partícula que pusponesta (sic) [pospuesta] forma preguntas. ba. partícula que junto a nombre propio hace dativo. ca. partícula que pospuesta significa solamente. da. partícula compocitiva (sic) [compositiva]. hi. partícula compocitiva con que se significa la causa y el porqué. yca. partícula compocitiva de mandar. ypa. partícula compocitiva que forman adjetivos. ma. partícula que forma plural. manga. partícula compocitiva. maquil i. masigca. partícula compocitiva para presente. $\mathrm{mi}$ - nag - nanga. partícula para futuro. ello.

Está claro que la metodología de trabajo que se muestra en el Diccionario de romance en lengua sugbuana de Francisco 
Encina incluye técnicas y métodos conocidos ya por la práctica lexicográfica del español. El conocimiento de las tradiciones hispánicas, a través de las obras misioneras de Nueva España, son un instrumento técnico absolutamente válido y avalado por la tradición española, en general, y la labor misionera en las Provincias, en particular. No debemos olvidar que Encina pone en práctica este conocimiento con un fin absolutamente instrumental: intervenir pedagógicamente en el dominio de la lengua cebuana por parte de los religiosos, lo cual se conseguía mediante la codificación en español, esto es, la transliteración de la lengua indígena para facilitar su consulta y aprendizaje, de manera que las voces filipinas debían de pronunciarse como si fuesen voces españolas.

\section{Traducción transmisora cultural}

El conato de evangelización en las misiones americanas y filipinas fue entendido como una actividad educativa que sienta sus principios en los mismos límites del Nuevo Testamento. ${ }^{4}$ La evangelización seguía directamente la praxis peninsular española ensayada en la labor de cristianización

\footnotetext{
${ }^{4}$ En un momento histórico tan marcado por la ley cristiana la actitud y talante no pretende sino seguir fielmente los designios de Dios: "Está escrito en la Ley —nos dice el Apóstol de los gentiles (1 Corintios, 14: 21)—: Por boca de lenguas extrañas y por boca de extraños hablaré yo a este pueblo" (cf. Isaías, 28: 11-12). De modo que la evangelización aparece impulsada por el Espíritu de Pentecostés: "la gente se congregó y se llenó de estupor al oírles hablar cada uno en su propia lengua [...] todos les oímos hablar en nuestra lengua las maravillas de Dios" (Hechos de los Apóstoles, 2: 11), y este espíritu es el que se mantiene constante en las misiones de predicación del evangelio. Igual se relata en las primeras evangelizaciones, a saber, en la evangelización de la Iglesia en Efeso: "Y, habién-
} 
del mundo árabe, donde el planteamiento de atraer a la fe católica a todos los vasallos tributarios de la Corona favoreció más los valores pedagógicos que el carácter puramente evangelizador. De este modo se establece que la predicación evangélica y administración de los sacramentos necesariamente debían de hacerse en el "idioma común y perceptible á los naturales del país", como bien señala el padre franciscano Cañes en el prólogo a su Diccionario español-latino-arábigo (1787). Sin duda, se veía en esta práctica, "hablar en lenguas", la restauración de la unidad perdida en Babel, labor maravillosa de la misión universal de los apóstoles.

Fruto de ello es el mérito más significativo y original al mismo tiempo que desconocido de estos diccionarios hispano-filipinos: la traducción transmisora cultural que resulta de esta actividad. Como bien señala Borao: "se quería verter una fe propia y cultura en una lengua ajena" (2013: 36).

La práctica de la evangelización misionera hizo que estos religiosos pronto se convirtieran en sujetos-traductores y que las misiones funcionaran como "agentes de una política lingüística” (Barros, 1990: 40). Así, los medios lingüísticos para alcanzar el fin del adoctrinamiento impusieron en su base las orientaciones y directrices necesarias para regir la actuación de los religiosos. En tanto a la lexicografía se refiere:

1) la creación de obras de carácter normativo a fin de resolver dudas de tipo lingüístico, especialmente de tipo

doles Pablo impuesto las manos, vino sobre ellos el Espíritu Santo y se pusieron a hablar en lenguas" (Hechos de los Apóstoles, 19: 5-6). 
léxico-semántico, lo que hizo que el diccionario se presentara como un texto fijado y con valor de traducción legítima;

2) el desarrollo de estrategias de control de equivalentes léxicos entre la (L1) y (L2) para sus obras lingüísticas, en este caso, entre el español y las lenguas filipinas; $y$

3) la formación de un grupo de religiosos reconocidos como poseedores e intérpretes legítimos de la fe cristiana.

\subsection{Traducción de los referentes religiosos propios de la fe cristiana}

La iniciativa y la decisión final sobre la selección del léxico religioso en las lenguas filipinas quedaban en manos del misionero. Si bien es cierto que se crearon instrumentos generales dedicados a la atención pastoral del indígena, entre los muchos que se podrían citar, cabe destacar uno de los más célebres y que más influyó en los tratados pastorales posteriores: el manual del siglo xviII del agustino Manuel Pérez, Farol indiano (México, 1713). En su primer tratado, dedicado al bautismo, Pérez afirma: "el Bautismo hecho en Lengua Mexicana es muy dudoso porque no explica lo que es el verbo Baptizar" (Saranyana y Alejos-Grau, 2005: 286). Por lo que queda patente las dudas de traducción que ofrecían ciertos términos religiosos.

De modo que, para algunos, tal y como es el caso de Fr. Francisco Encina, Dios y otras palabras cristianas como bendita, misa, padrino del baptismo y reliquia eran intraducibles. Este léxico tocante a cuestiones relacionadas con la divinidad, la santidad, la celebración de la eucaristía y la 
persona que ejerce una paternidad espiritual sobre sus ahijados en el sacramento del bautismo no ofrecen equivalente en cebuano. Encina declara que estas voces son en lengua cebuana "ydem" al castellano.

Sin duda, el sentimiento de recelo a traducir este léxico se justifica al entender el lenguaje no solo como contenido, sino como simbolización, es decir, que el significado es una estructura conceptual convencionalizada que está representado en una estructura gramatical convencional. La ruptura de los convencionalismos mediante la praxis traductológica supone, por tanto, la pérdida de la esencia conceptual básica, sobre todo, si se entiende que existe un nexo real entre la palabra y su significado. Así se interpreta en la documentación teológica americana de la época colonial, según Manuel Pérez, a propósito de la voz bautizar, señala: "siempre que se muda la significación total que es quasi substancial de las palabras de la forma, no hay Sacramento (p. 9)" (Saranyana y Alejos-Grau, 2005: 286).

No obstante, esta creencia no se lleva a la práctica de manera absoluta, de ahí que, por ejemplo, en el Diccionario hispano-cebuano, Francisco Encina sí reinterprete otras voces. Palabras castellanas, como las propias de las ceremonias religiosas y prácticas rituales más básicas, principalmente la oración, así como los sentimientos de veneración y temor hacia la divinidad cristiana, estas, sí tienen sus equivalentes en lengua cebuana, en (15). Del mismo modo, se ofrece un equivalente en lengua indígena para reconocer la propia colectividad e institución de los misioneros, en (16).

(15) Traducción de los referentes religiosos propios del catolicismo: 
bautizar. Buñag.

bautisterio. buloñagan.

bendecir. dalangin.

bendito. qui dalanginan.

biblia. santos nga sulat.

gracia de dios. hatag .i. calooy sadios.

gracia devina. hatag nga dios non.

oración. pagampo i. pangamois.

orar. pangadye.

oración plegaria. Dalangino.

orden o mandamiento. sugo.

orden sacro. pag pari.

pecado. sala.

pecado contra naturam. labut suhingasala.

pecador. macasasala.

santiguarse. pangunos.

(Encina, m. s. XVIII: s.v.)

(16) Traducción de los referentes religiosos propios de los misioneros:

religión y observancia. lehe.

religión o congregación de religiosos. caparian.

religioso o christiandad. pagca christianos.

(Encina, m. s. XvinI: s.v.)

Sin duda, como bien afirma Ameal: "el criterio de traducción fue muy moderado debido al posible consenso entre los misioneros y las autoridades" (2004: 82). Es así que en la obra de Encina, la traducción de los referentes religio- 
sos propios de la fe cristiana se presenta en un listado de léxico evangélico básico y de urgencia para las tareas de la misión. Fuera de esto no hay otra pretensión ideológica que buscar la claridad de representación de las nuevas ideas y conceptos que exportó la misión para el mundo indígena e infundirlos e inculcarlos en los ánimos de las nuevas almas convertidas. De ahí que como voz sacramental, solo se liste y traduzca la del bautismo, sin duda, primera actuación e inmersión religiosa para la conquista espiritual.

\subsection{Denominación de las nuevas realidades indígenas}

Otra cuestión a destacar en la obra de Encina es la identificación e interpretación de palabras cebuanas que representan nuevas realidades conceptuales para el castellano. Es, sin duda, en esta tarea en la que el traductor pone en marcha su capacidad pedagógica para hacer llegar la interpretación del Nuevo Mundo a través de los convencionalismos y conocimientos castellanos.

En el Diccionario de Francisco Encina no hay una incorporación y adaptación castellana de indigenismos, a diferencia de lo que se puede encontrar en otras obras semejantes o en el mismo repertorio académico que pronto dio buena muestra de acogida al léxico filipino (Quilis y Casado, 2008).

La realidad indígena se ofrece a través del léxico que representa realidades, especialmente, de especies animales $\mathrm{y}$ vegetales. Y dado que, como hemos señalado, no incorpora indigenismos adaptados, la técnica de traducción lo lleva a hacer uso del hiperónimo general que identifica la 
especie, en (17). Así mismo se sirve de la expresión especie de antepuesta al nombre propio de la cultura española para indicar que el ser o la cosa de que se trata es muy semejante a lo que el nombre en lengua cebuana designa. La rentabilidad que ofrece el uso de esta expresión debe entenderse como un medio altamente productivo, ya que permite la especificación detallada del significado mediante del correlato léxico que acompaña a la estructura sintagmática, en (18). También hace uso del adjetivo cierto/a precediendo inmediatamente al sustantivo mostrando un sentido indeterminado que solo adquiere significado pleno en el equivalente filipino, en (19).

Es de esta manera que Encina hace remisiones, identificando animales filipinos o especies vegetales filipinas con las propias del continente europeo, aunque no podemos creer que con ello proponga una filogenia parental entre los grupos emparentados, habida cuenta de que el misionero es consciente de que se oponen en el hábitat y en su concepción en el seno de la sociedad. Es más una proyección de la lengua materna hacia la realidad y lengua indígena.

(17) Voces cebuanas de animales y vegetales identificadas por su hiperónimo:

fruta a modo de azeitunas. pajo.

gallo a modo de árbol cubí. cubihon.

yerva que tiene las ojas agudas. daat.

yerva especie de agengibre. lampuiang.

yerva que pega en la ropa la fruta. mandiong.

yerva especie de tomates. hulagtub.

pájaro como las palomas. tandoloc.

pájaro especie de perico. colansi. 
pájaro que por canto le llaman. olol. peze especie de sardinas. malalangsi. peze especie de sardinas. calomaray.

(18) Voces cebuanas de animales y vegetales identificadas por el correlato léxico que sigue a la expresión: especie de...

especie de lagartija. tabili.

especie de lirio. palagion.

especie de caña dulze. pinalina.

especie de frijol. parani. bulay.

especie de cocos enanos. pilipinos .i. danili.

especie de arbusta midicinal. lagtano.

especie de jongos (sic) [hongos] venenosos. puclilay.

especie de hormigas negras y grandes. mantic magpala tay ng halas.

(Encina, m. s. xviII: s.v.)

(19) Voces cebuanas de animales y vegetales identificadas por el sustantivo modificado por el adjetivo indeterminado: cierto/a

cierto arezefe (sic) [arrecife] a modo de estrilla (sic) [estrella]. lapalapa.

cierta trampa para coger pájaros. batagan.

cierto gozano (sic) [gusano] pelodo (sic) [peludo]. til-as.

cierto gozano (sic) [gusano] venenoso. basol.

(Encina, m. s. XVIII: s.v.) 
Como vemos, estas voces, aunque poseen un significado referencial, carecen de significante en el lexicón castellano. Denotan nuevas realidades y se registran dentro de un saber que está en continuo movimiento y descubrimiento. Casi podríamos decir que Francisco Encina da de ellas una primera identificación.

\section{Conclusiones}

El Diccionario de romance en lengua sugbuana (mediados s. XVIII) de Fr. Francisco Encina nos ofrece características sobresalientes, es, sin duda, una herramienta de trabajo, útil en su sencillez y disposición y alejada de artificios y de toda pretensión artística y no exento de errores lingüísticos en su parte castellana. Es un texto en el que se proyecta las experiencias lingüísticas personales y se pone en práctica un proyecto de traducción como método de evangelización misionera. Ofrece algunos rasgos peculiares y muchos compartidos con la producción y práctica lexicográfica que nos trae la historiografía hispano-filipina de esta época.

No obstante, debemos tener presente que la investigación actual señala que la mayoría de los expertos en lexicografía hispánica bilingüe nunca han examinado con detenimiento estas obras y, cuando se ha hecho, ha sido con muchas limitaciones.

A partir de 1809 los estados americanos empezaron a declararse independientes y los religiosos españoles fueron expulsados por decreto. Igualmente, como consecuencia de la revolución filipina en 1898, la Provincia también 
tuvo que abandonar, a fines del siglo XIX, todos los puestos de apostolado en el archipiélago asiático. Sin embargo, todavía hoy podemos encontrar rastros de su labor lingüística en estas tierras. En muchos casos, solo tenemos noticias que nos llegan desde las mismas crónicas de los religiosos misioneros. Felipe II había favorecido la proliferación de crónicas, animando a los religiosos a redactar informes detallados de la misión. Estas crónicas se presentan como una documentación preciada para conocer la labor de estos religiosos dentro de las letras, ya que muchas de las obras que se redactaron, gramáticas y vocabularios que describían las lenguas indígenas, hoy están desaparecidas. Y las que no tuvieron este final, están dispersas en archivos americanos y asiáticos e incluso en instituciones ajenas a la Orden. Muchas, aún, como esta que nos ocupa, en estado manuscrito.

En un mundo lleno de creencias y dogmas, normas éticas y morales de comportamiento social e individual y prácticas rituales de oración, el diccionario redundó en una herramienta clara y formal para la evangelización de las almas infieles, al tiempo que la práctica traductora lograba la instrucción en la doctrina de la salvación.

\section{Bibliografía}

Alonso Araguás, Icíar (2005), Intérpretes de Indias. La mediación lingüistica y cultural en los viajes de exploración y conquista: Antillas, Caribe y Golfo de México (1492-1540). Tesis doctoral. Disponible en línea [consultado: 01/04/2016]: http://gredos.usal.es/jspui/bits- 
tream/ 10366/16145/2/DTI_AlonsoIciar_InterpretesIndias.pdf.

Ameal Pérez, Alberto Jorge (2004), "Problemas de traducción de textos misioneros del siglo XVI en América Hispánica”, en C. Cazorla et alii (coords.), Estudios de Historia de la Lengua e Historiografía Lingüística. Actas del III Congreso Nacional de la Asociación de Jóvenes Investigadores de Historiografía e Historia de la Lengua Española (Jaén, 27-29 de marzo 2003), Madrid, CERSA, pp. 75-83.

Barros, María Cándida D. M. (1990), "La palabra de Dios en la lengua del otro", Iztapalapa, 29, pp. 40-53.

Bergaño, Diego (1729), Arte de la lengua pampanga compvesto por... Fr. Diego Bergaño del orden de los Hermitaños de Nuestro Padre San Agustín, Manila, Imprenta de la Compañía de Iesus, por Don Sebastián López Sabino.

Bergaño, Diego [1732] (1860), Vocabulario de la lengua pampanga en romance, Manila, Impr. de Ramírez y Giraudier.

BNE, Inventario General de Manuscritos. Tomo XII (7001 a 8499), Madrid, Ministerio de Cultura. Dirección General del Libro y Bibliotecas, 1988. Disponible en línea [consultado: 01/04/2016]: http://www.bne.es/es/ Micrositios/Guias/Inventario_ Manuscritos/Introduccion/.

BNE, Biblioteca digital Hispánica. Disponible en línea [consultado 01/04/2016]: http://www.bne.es /es/Catalogos/ BibliotecaDigitalHispanica/Inicio/. 
Borao, José Eugenio (2013), "La «Escuela de traductores de Manila»: Traductores y traducciones en la frontera cultural del Mar de China (siglos xvi y XVII)", en I. Donoso Jiménez (ed.), Historia cultural de la lengua española en Filipinas: ayer y hoy, Madrid, Verbum, pp. 23-52.

Encina, Francisco, Diccionario de romance en lengua sugbuana [mediados s. XviII]. Disponible en línea [consultado: 01/04/2016]: http://bdh.bne.es.

García-Medall, Joaquín (2004), "Notas de lexicografía hispano-filipina. El Bocabulario de lengua bisaya, hiligueyna y haraya de la isla de Panay y Sugbu y para las demás islas, de Fray Alonso de Méntrida, OSA (CA.1637)", en O. Zwartjes y E. Hovdhaugen (eds.), Missionary Linguistic/Lingüística Misionera: selected papers from the First International Conference on Missionary Linguistics, Ámsterdam, John Benjamins, pp. 201-232.

García-Medall, Joaquín (2007), "La traducción codificada: las artes y vocabularios hispano-filipinos (16101910)", Hermēneus. Revista de Traducción e Interpretación, 9, pp. 1-21.

Quilis, Antonio y Celia Casado Fresnillo (2008), La lengua española en Filipinas: historia, situación actual, el chabacano, antología de textos, Madrid, CSIC.

Ridruejo, Emilio (2001), "Las primeras descripciones gramaticales de las lenguas filipinas (s. XviI)", en J. Calvo Pérez (ed.), Contacto interlingüístico e intercultural en el mundo hispánico, Valencia, Universitat de València, vol. 2, pp. 529-553. 
Ridruejo, Emilio (2003), "Las primeras gramáticas del náhuatl y el proceso de gramatización de las lenguas filipinas", en E. Ridruejo y M. Fuertes (coords.), I Simposio Antonio Tovar sobre Lenguas Amerindias, Tordesillas (Valladolid), IIEIP-UVa, pp. 117-139.

Romero Rangel, Laura (2013), "Innovaciones lexicográficas del primer diccionario de la Nueva España: el Vocabulario castellano-mexicano (1555) de Alonso de Molina", Revista Argentina de Historiografía Lingüistica, V, 1, pp. 41-62.

Santiago Vela, Gregorio de (O.S.A.) (1922), Ensayo de una Biblioteca Iberoamericana de la Orden de San Agustín, vol. 8, El Escorial, Imprenta del Monasterio.

Saranyana, José Ignacio y Carmen José Alejos-Grau (2005), Teología en América Latina: Escolástica barroca, ilustración y preparación de la Independencia (16651810), II-1, Vervuert, Iberoamericana.

Sueiro Justel, Joaquín (1999), "Panorama de la lingüística española en Filipinas", en M.-C. Henríquez Salido y M.-Á. Esparza (eds.), Estudios de historiografía lingüística hispánica ofrecidos a H.J. Niederehe, Vigo, Universidade de Vigo, pp. 123-142.

Zimmermann, Klaus (2004), "La construcción del objeto de la historiografía de la lingüística misionera", en $\mathrm{O}$. Zwartjes y E. Hovdhaugen (eds.), Missionary Linguistic/Lingüistica Misionera: selected papers from the First International Conference on Missionary Linguistics, Ámsterdam, John Benjamins, pp. 7-32. 